\title{
Optimization of Passive Flat Plate Solar Thermal Collector
}

\author{
${ }^{1}$ Yusuf Abdulmalik and ${ }^{2}$ Sani Aliyu \\ ${ }^{1}$ Department of Physics, Federal University Gusau \\ ${ }^{2}$ Department of Physics, Usmanu Danfodiyo University Sokoto \\ Nigeria
}

\begin{abstract}
Solar flat plate collector with a triple-glazed cover was designed and constructed using locally available materials. The design was an upgrade of the existing double-glazed flat plate collector available at Sokoto Energy Research Center, Sokoto. The solar energy penetrates through the glass cover and is received by the absorber plate, which is coated black in order to absorb as much thermal energy as possible. The heat energy supposed to escape the collector after received in the collector is then trapped by the glass cover of up to three layers which serve as a good insulator, thereby reducing the heat loss. Some design parameters were done considering the geographical location of the test site. The collector has a dimension of $90 \mathrm{~cm} \mathrm{X} 100 \mathrm{~cm}$, poly urethane foam was used for insulating the collector, the absorber plate was painted with a black dull paint with the emissivity of 0.95. The collector was able to heat up to a temperature of $55.9^{\circ} \mathrm{C}$, and the system efficiency was $14 \%$ which is much better than the conventional flat plate collector with double glazing whose efficiency was 11.1 percentage.
\end{abstract}

Keywords: Solar water heater, Flat plate collectors, Efficiency, Global warming, Glazing.

\subsection{INTRODUCTION}

The world's energy supply is based on the non-renewable sources of energy such as oil, coal, natural gas and uranium which are all exhaustible and have adverse effects on the ozone layer, resulting to global warming. In order to avoid this great threat to the environment. One of the easiest and most direct applications of this energy is the conversion of solar radiation into heat (Rahul et. al., 2016).

Solar water heaters are devices used to heat water by simply using energy obtained from the sun. the sun reaching the earth surface in form of electromagnetic radiation (Munish and Sharma, 2014) is therefore received by solar thermal collector.

Eze and Ojike (2012) were able to obtain thermal efficiency of a single-gazed flat plate collector to be $42 \%$. The performance of flat plate collector over different geometric absorber plate was analyzed by Amrutkar et. al., (2012) and the efficiency of 55\%$70 \%$ was obtained.

The aim of this work is toimprove the performance of flat plate collector by increasing the number of glass cover from double to triple.

\subsection{MATERIALS AND EXPERIMENTAL PROCEDURES}

\subsection{Materials}

- $\quad$ Digital Thermocouple Data Logger

- Thermo-Anemometer

- $\quad$ Pyranometer

- $\quad$ Measuring Beaker

- $\quad$ Cello tape

- Digital Balance

- $\quad$ Stop Clock

- $\quad$ Connecting wires

- $\quad$ Evacuated tube collector

- $\quad$ Flat plate collector 
- $\quad$ Mild Steel Iron

- Glass

- $\quad$ Polyurethane foam

- Galvanized steel pipes

- Gum

- Wood

\subsection{Experimental Procedures}

Some of the methods employed in conducting this research are:

i. Data collection from available literature on works that relate to solar water heating using flat plate collector and evacuated tube collector.

ii. Testing and adopting the existing flat plate collectors i.e. double-glazed.

iii. Selection of appropriate construction materials of the triple-glazed flat plate collector based on the locally available materials.

In order to evaluate the performance of the flat plate solar collectors, measurements of temperature $\left({ }^{\circ} \mathrm{C}\right)$, wind speed $(\mathrm{m} / \mathrm{s})$, solar radiation intensity $\left(W^{-2}\right)$, were recorded.

Both the Ambient temperature, the inlet and outlet temperature of each system was measured using a digital thermocouple, the wind speed was measured using a Thermo-anemometer. As for the solar radiation and Pyranometer was used in measuring the solar radiation intensity.

Thermocouple Data Logger was used to measure the ambient temperature, the inlet and outlet temperature of each of the system. The thermocouple has a set of six wires to be connected to source of heat, meaning the wires can be connected to six different sources instantaneously and the temperatures will be displayed at the channel assigned to that particular wire. Each wire was taped to the source (the inlet pipe, outlet pipe) using a cello tape, while the ambient temperature was obtained by suspending one of the wires in the air. The various temperatures were displayed on the screen of the Thermocouple data logger and recorded.

Thermo-anemometer was used in measuring the wind speed at the same time that both temperature and solar radiation were measured. The thermo-anemometer was held up in the air at about two-meters $(2 \mathrm{~m})$ high at the test site. The thermo-anemometer vane was pointed towards the direction of the wind, and this was easily known by the help of the wind turbines located around the site because the wind direction varies momentarily.

Pyranometer was used to measure the Solar radiation intensity. The Pyranometer was placed in the midst of the different collectors, with the sensor facing the sky. The location of the Pyranometer was monitored and altered, because when left at a particular position near the collectors, there will be shading by either of the systems. Hence, before recording the value of Solar radiation intensity, the sensor must be observed and noted if it is facing the sky without interruption.

The test was carried out over a period of three days for each of the systems, starting from 10am in the morning to $4 \mathrm{pm}$ in the evening.

\subsubsection{Determination of Collector Efficiency}

Collector efficiency is obtained by the ratio of the average heat output from the collector divided by the rate that the solar radiation strikes the collector i.e.

$\eta=Q / A_{c} G_{T}$

But $Q=m C_{p}\left(T_{o}-T_{i}\right)$

So, Equation (1) becomes:

$\eta=m C_{p}\left(T_{o}-T_{i}\right) / A_{c} G_{T}$

Where,

$\eta$ is the efficiency

$\mathrm{m}$ is the flow rate of the fluid in $\mathrm{Kg} / \mathrm{mins}$.

$C_{p}$ is the specific heat capacity of the fluid $J \mathrm{Kg}^{-1} \mathrm{~K}^{-1}$.

$T_{o}$ is the fluid outlet temperature from the absorber in ${ }^{\circ} \mathrm{C}$. 
$T_{i}$ is the fluid inlet temperature towards the absorber in ${ }^{\circ} \mathrm{C}$.

$A_{c}$ is the area of the collector in $m^{2}$.

$G_{T}$ is the beam radiation in $W m^{-2}$.

$Q$ is the quantity of heat in $J$.

\subsection{Theoretical Consideration}

\subsubsection{Flat Plate Collector}

A flat-plate collector (FPC) is the heart of a solar water heating system and it is commonly used for harvesting solar thermal energy at low ambient temperatures (Struckmann, 2008). It consists of: a selectively coated flat-plate absorber plate, a transparent cover (usually double-glass cover) to reduce top heat-losses from the absorber plate (Manikandan and Sivaraman, 2016), heattransport fluid (HTF) to remove heat from the absorber plate, tubes for the flow of the HTF, a heat insulating support to reduce heat loss from the collector, and a protective casing to ensure the components are free from dust and moisture (Anand et. al., 2011). In addition, flat plate collectors do not have optical concentration of sun light and they are generally stationary and produce a temperature below $90^{\circ} \mathrm{C}$ (Anand et al., 2011). The absorber plate maybe made of copper, steel, galvanized iron, aluminum sheets or plastic (Amrutkar et al., 2012).

A flat plate collector collects both direct component of solar radiation and diffuse solar radiation, and their total solar irradiance is used as the basis for flat plate collector performance calculation (Sadik, 2013). They are usually fixed permanently in a particular position and hence require no tracking of the sun (Kaligorou, 2004).
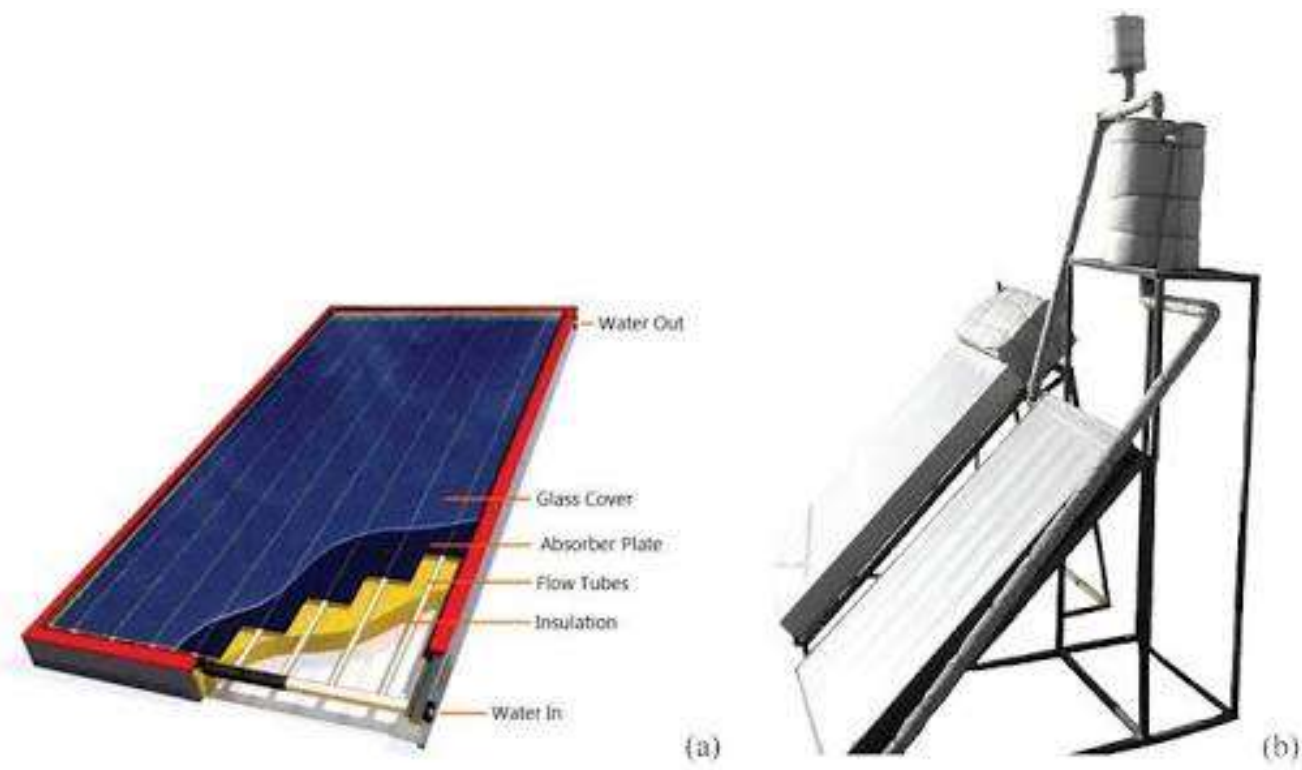

Figure 1: Flat Plate collector

\subsubsection{Thermosyphon Principle}

In this case, cold water flow down to the collector due to gravity where it absorbs thermal energy from the sun. This results to the density becoming lesser (natural convection), thereby causing the heated water (with less density) to rise through the riser pipes back to the tank. Passive collectors which operates on the principle of thermosyphon usually have low flow rates (Basil, 2013) compared to the active systems. 


\subsection{DESIGN}

\subsection{Design Concept}

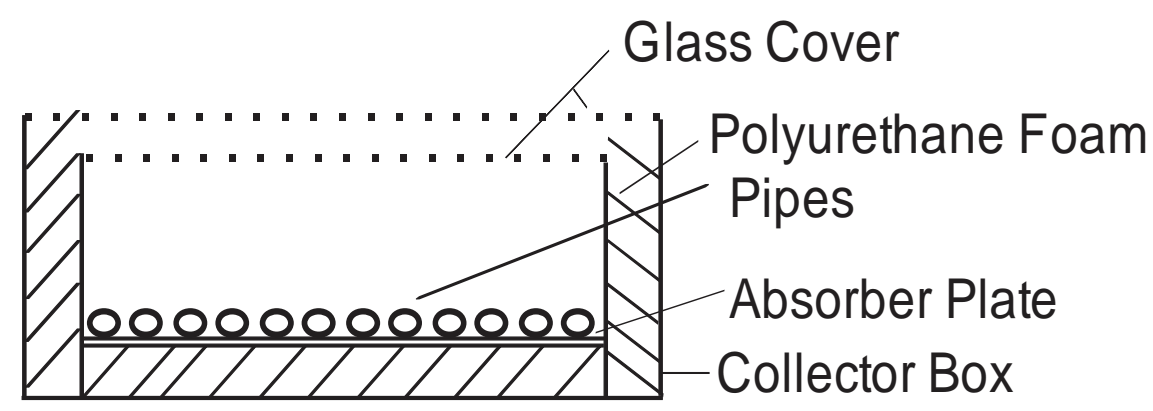

Figure 2: Conventional flat plate collector with double-glazed cover

Figure 1 shows a conventional flat plate collector already designed and installed at Sokoto Energy Research Center. As seen in Figure 1 the collector's cover has two glasses.

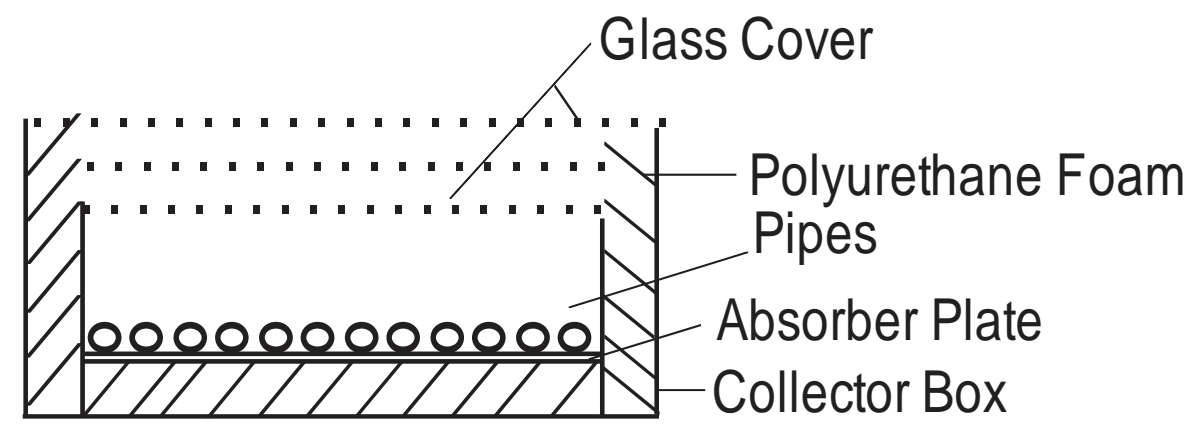

Figure 3: Modified flat plate collector with triple-glazed cover

\subsection{Design Analysis}

\subsubsection{Collector Orientation}

The orientation of the collector is based on two factors namely; Azimuth angle and Tilt angle

\subsubsection{Azimuth Angle}

In the northern hemisphere where Sokoto (the location of the collector) is located, the azimuth angle of fixed surface due south (Rikoto et. al., 2015), hence the collector should face south.

\subsubsection{Tilt Angle}

The tilt angle of fixed flat plate collector is equal to the latitude of the location (Rikoto et. al., 2015). The collector is tilted $13^{\circ}$ to the horizontal surface in line with the latitude of Sokoto.

\subsection{Selection of materials}

In the selection of the materials used in constructing the collector factors like availability of materials, simplicity in construction and maintenance are considered. The materials selected are discussed below.

\subsubsection{Glazing}

In the selection of glazing material, glass was used even though there are cheaper and more resistant to breakage materials like plastic, their main disadvantage is that their transmittance for long wavelength is also high and thereby making it not a good heat trap as compared to glass (Rikoto et. al., 2013).

\subsubsection{Absorber plate}

The choice of mild steel iron was used for making the absorber plate, because it is cheap compared to other choices such as copper, aluminum, galvanized iron with higher thermal conductivity (Rikoto et. al., 2013).

\subsubsection{Collector casing}

The collector casing is what holds all other components of the collector. Mild steel and wood was used because of their availability and cheapness in the local market.

\subsubsection{Pipes}


In selecting pipes for the collector, factors like rigidity, corrosion, availability have to be checked, and as such, the choice of galvanized steel pipes were made.

\subsubsection{Insulator}

Polyurethane foam was used to insulate the collector. This choice was made considering the availability and cheapness in the local market, compared to other commonly used insulators such as Styrofoam, saw dust, wool, rice husk etc. (Rikoto et. al., 2013).

\subsection{Collector construction}

The step by step procedure of constructing the collector is as follows:

i. Metal sheet was measured and cut to the size of the collector (i.e. $90 \mathrm{~cm} \times 100 \mathrm{~cm}$ ).

ii. $\quad$ inch galvanized pipe was measured and cut to the required length of the header $(86 \mathrm{~cm})$.

iii. $1 / 2$ inch galvanized pipe was measured and cut to the required length of the riser $(95 \mathrm{~cm})$.

iv. The header pipe was drilled with holes slightly bigger than the size of the riser pipes in order for the riser pipes to be fixed for welding.

v. The welded header and riser were placed on the absorber plate and welded together.

vi. A wooden box was constructed to fit the heat exchanger.

vii. Rectangular flat bar and square pipes were cut and welded to serve as frame for the transparent glass cover.

viii. The glass was cut in three place and fixed in the frame.

ix. The poly urethane insulation foam was cut to fit all the collector insulation.

x. And finally the collector was assembled.

xi.

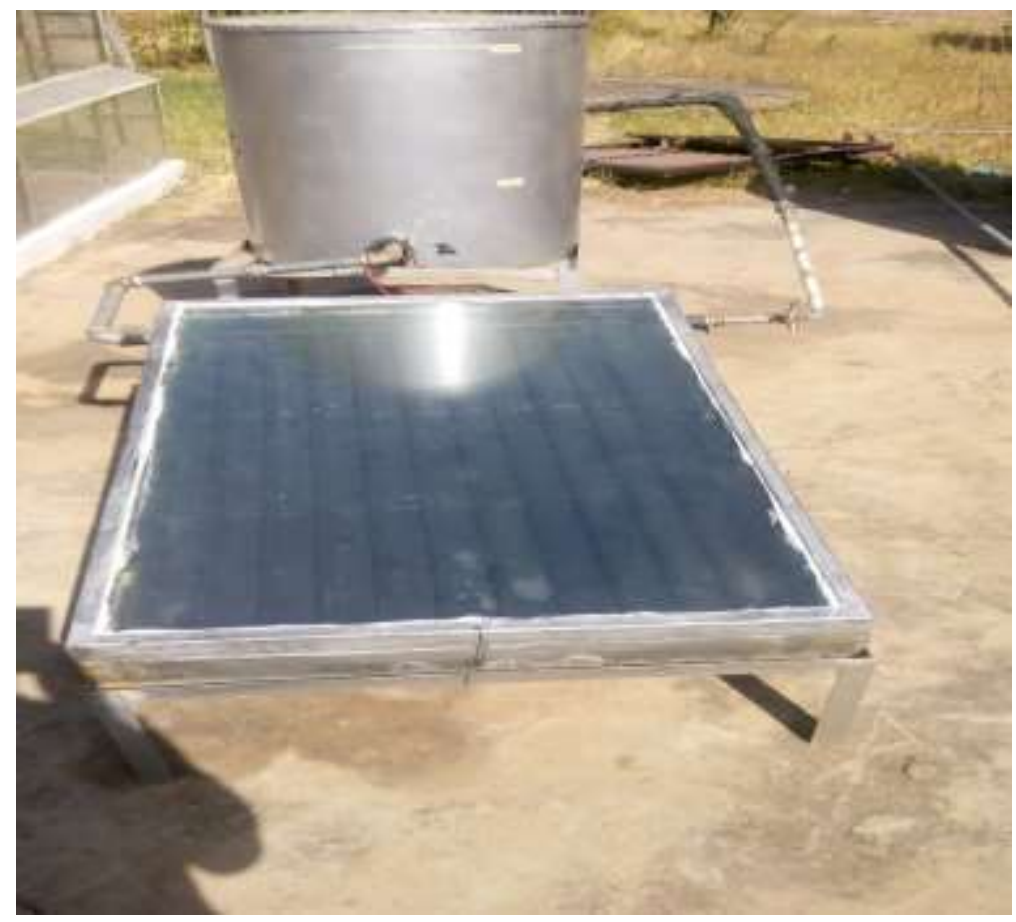

Figure 3: Triple-glazed flat plate collector installed at Sokoto Energy Research Center Sokoto

\subsection{RESULTS AND DISCUSSION}

The test results obtained from Flat Plate Solar thermal collector with double glazing (i.e. double glass cover) under various climatic conditions are presented in Figure 4 and Figure 5. It shows the Variation of Temperature (Ambient, Inlet and Outlet Temperature) with Beam Radiation obtained on $15^{\text {th }}$ November, 2017 and $17^{\text {th }}$ November, 2017 respectively. 
International Journal of Advances in Scientific Research and Engineering (ijasre), Vol 5 (4), April-2019

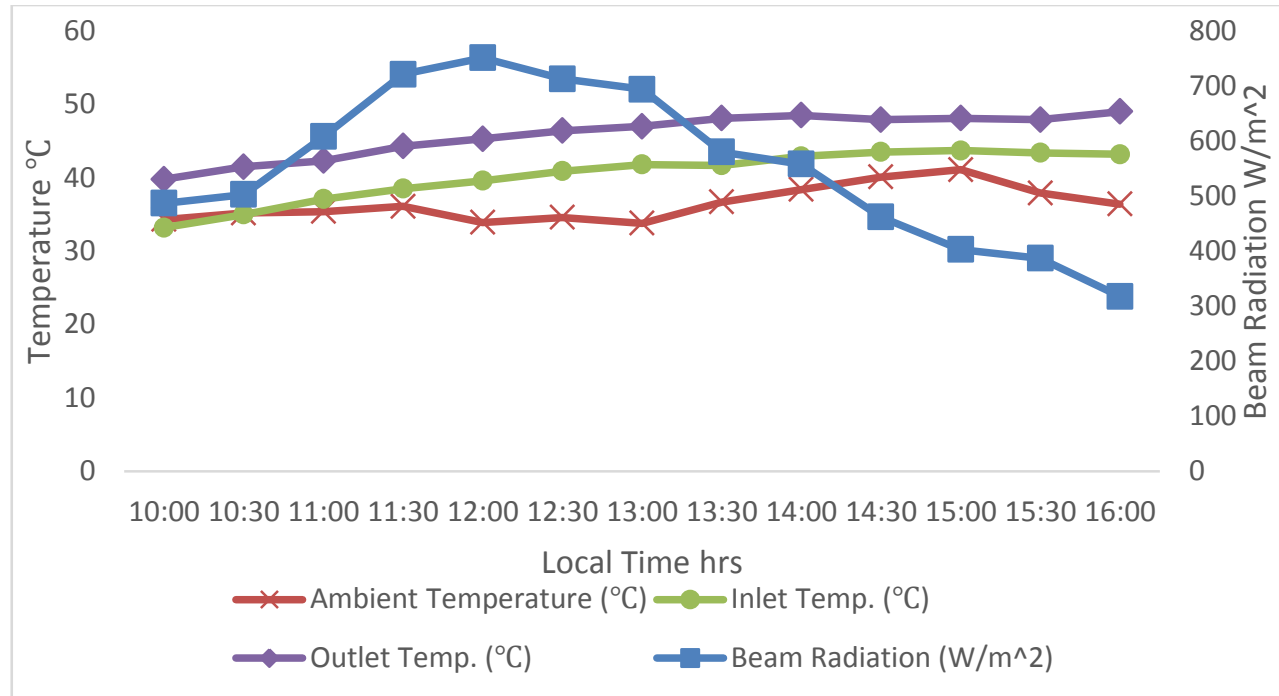

Figure 4: Temperature Variation with Beam Radiation of Double-Glazed Flat plate

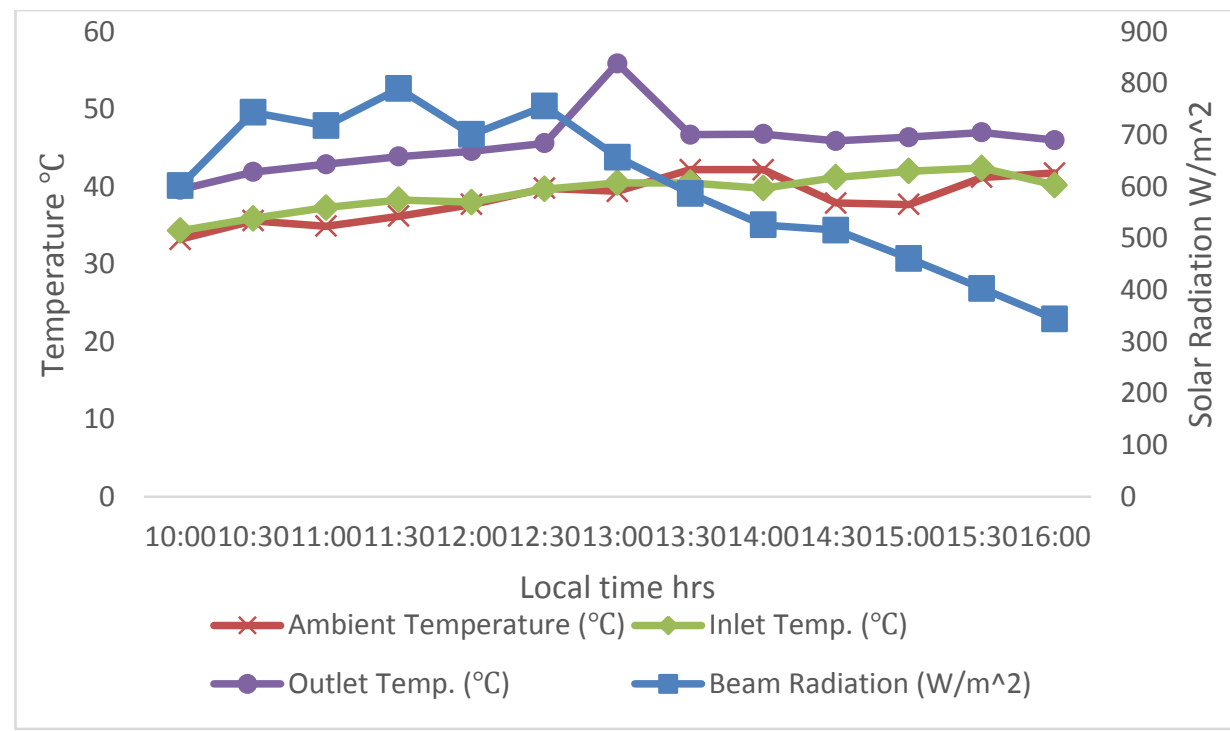

Figure 5: Temperature Variation with Beam Radiation for Triple-glazed Flat Plate

It can be seen in Figure 4 that the temperature difference tends to be regular with the largest difference at exactly 2:00pm when the Beam Radiation $558 \mathrm{Wm}^{-2}$. The Beam Radiation was at that point dropping but the Ambient temperature seems to be fluctuating. The maximum outlet temperature recorded for the double-glazed flat plate collector was $49^{\circ} \mathrm{C}$ which was obtained at the last hour of the test i.e. $4: 00 \mathrm{pm}$. Upon calculating the efficiency of the system using the parameters of the system at hour with the maximum outlet temperature of the collector. The efficiency of the system was found (using equation 3) to be 11.1\%.

As for the flat plate collector with triple glazed cover, the efficiency of the system was calculated to be $14 \%$ using the parameters at the hour in which the outlet temperature of the collector was maximum. This can be seen in Figure 5, the maximum outlet temperature recorded was at exactly $1: 00 \mathrm{pm}$. The temperature was $55.9^{\circ} \mathrm{C}$ and the beam radiation at this point was $657 \mathrm{Wm}^{-2}$.

\subsection{CONCLUSION}

From the result obtained it is evident that the optimized flat plate collector with triple-glazed cover perform much better than the convention flat plate collector with double-glazed cover with efficiencies of $14 \%$ for the triple-glazed and $11.1 \%$ for the doubleglazed flat plate collector. Hence, the triple-glazed flat plate collector is a better system and the best choice for domestic use and local agricultural processing. 


\section{REFERENCES}

1. Rahul, D. G, Vipin, B. N. and Mayuri, M. W. (2016), Performance Analysis of Flat Plate Solar Water Collector using Trapezoidal Shape and Semi-circular Tubes, International Journal for Research in Applied Science and Engineering Technology, 4(8).

2. Basil, O. (2013), Thermo Siphon Solar Water Heater, International Journal of Engineering and Technology, 3(3).

3. Munish, K. and Sharma, V. K. (2014), Latest Evolutions in Flat Plate Solar Collectors technology, International journal of Mechanical Engineering, 1(1).

4. Eze, J. I. and Ojike, O. (2012), Analysis of Thermal Energy of a Passive Solar Water Heater, International Journal of Physical Sciences, 7 (22), 2891-2896.

5. Amrutkar, S. K., Ghodke, S. and Patil, K. N. (2012), Solar Flat Plate Collector Analysis, International Organization of Scientific Research Journal of Engineering, 2 (2), 207-213.

6. Struckmann, F. (2008), Analysis of flat plate collectors, Project report: Department of Energy Sciences, Faculty of Engineering, Lund University, Sweden. Pp.2-3.

7. Manikandan, J. and Sivaraman, B. (2016), Comparative Studies on Thermal Efficiency of Single and Double Glazed Flat Plate Solar Water Heater, ARPN Journal of Engineering and Applied Sciences, 11 (9), 5521-5526.

8. Anand, B., Dass P. P. and Rajeev, J. (2011), Parametric studies of top heat loss coefficient of Double-glazed Flat plate solar collectors, MIT international Journal of Mechanical Engineering, 1 (2), 71-78.

9. Sadik, U. (2013), Construction and Performance Evaluation of Parabolic Solar Concentrator for Steam Generation, MSc. dissertation, Department of Pure and Applied Chemistry, Usmanu Danfodiyo University Sokoto (unpublished).

10. Kaligorou, S. A., (2004), Solar Thermal Collectors and Applications, Progress in Energy and Combustion science, Pp.235-247. Retrieved on $22^{\text {nd }}$ September, 2016: www.elsevier.com/locate/pecs

11. Rikoto, I. I., Abdulrahman, M. B., Idris, M. H., Garba, M. M. and Halidu, M. K. (2015) Design, Construction and Installation of 250-Liter Capacity Solar Water Heating System at Danjawa Renewable,International Journal of Engineering Science, 4 (3), 39-44. 